\title{
The growth and development of rats given a low -protein diet
}

\author{
By J. W. T. DICKERSON \\ Department of Biochemistry, University of Surrey, Guildford \\ AND P. C. R. HUGHES AND P. A. MCANULTY \\ Department of Growth and Development, Institute of Child Health, \\ Guilford Street, London WCI NIEH
}

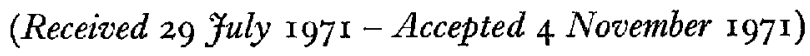

\begin{abstract}
I. Weanling (24-d-old) rats of a black and white hooded strain were allowed free access for $28 \mathrm{~d}$ to a diet containing $5 \%$ casein supplemented with methionine, and sucrose as the carbohydrate. Controls were fed on a $25 \%$ casein diet with a corresponding reduction in sucrose. Animals given the deficient diet were killed either at $52 \mathrm{~d}$ of age or after subsequent rehabilitation on the $25 \%$ casein diet when aged $\mathrm{I}_{4} 0 \mathrm{~d}$. These animals were compared with controls killed at these two ages and at the start of the experiment.

2. The skeletons were $X$-rayed, skeletal maturity was determined according to a scoring system, and various bones were measured. The forebrain and cerebellum were analysed for cholesterol and DNA and the brain stem for cholesterol only. The DNA content of the paired quadriceps muscles and the livers was also determined.

3. On the low-protein diet the body-weight rose by $7 \mathrm{~g}$ compared with the control value of Ir 5 g. On rehabilitation, the body-weight of the previously malnourished group showed the expected growth spurt, but failed to attain that of the controls at $140 \mathrm{~d}$.

4. With the exception of the pelvis width, all the bones grew a little during the period on the low-protein diet. After rehabilitation, the hind limb, pelvis, iliac and spine lengths and the bi-iliac width remained smaller than these measurements in the corresponding controls, whereas there was no difference in the length of the fore limb, width of the pelvis or in the bone maturity score.
\end{abstract}

5. The forebrains and cerebellums of the malnourished rats did not increase in weight, whereas some increase occurred in the brain stem. The concentration of cholesterol in the forebrains of the deficient animals was the same as that in controls of the same age, but on rehabilitation the concentration did not rise to the control value. The concentration of cholesterol in the cerebellum and brain stem of the deficient rats was lower than in controls of the same age but, whereas that in the cerebellum attained an almost normal level on rehabilitation, that in the brain stem remained significantly lower. The low-protein diet prevented the normal increase in cerebellum DNA and the amount remained low in the rehabilitated animals.

6. The experimental diet caused a complete cessation of growth of the quadriceps muscles, and even after rehabilitation they weighed less than their controls. The DNA content, however, was not significantly lower.

7. The low-protein diet did not permanently affect either the weight or DNA content of the liver.

Dietary restriction in rats during the first $2 \mathrm{I} \mathrm{d}$ after birth leaves a permanent impression upon certain aspects of their subsequent growth and development, even when they have access to unlimited food during the remainder of their lives. Thus, they never weigh as much as controls of the same age (Kennedy, I957-8; Widdowson $\& \mathrm{McCance}, \mathrm{I} 960)$, have lighter brains that contain lower concentrations of cholesterol and a smaller amount of deoxyribonucleic acid (DNA) and presumably, a smaller number of cells (Winick \& Noble, I 966; Dobbing, I 968). More severe undernutrition during the gestation period as well as the suckling period results in a permanent stunting of the growth of some, but not all, bones in the skeleton (Dickerson \& Hughes, 1972). Comparatively few studies have been made, however, of the effects of dietary 
restriction after weaning on the subsequent growth and development of the rat. The growth and development of the brain with respect to cholesterol, phospholipids and DNA have been shown not to be permanently retarded (Winick \& Noble, 1966; Dobbing \& Widdowson, 1965; Dickerson \& Walmsley, 1967), whereas Winick \& Noble (1966) found that the growth and DNA content of skeletal muscle and liver were permanently retarded by undernutrition during the 3 weeks immediately after weaning.

In the experiments on weanling rats reported by Dickerson \& Walmsley (I967) the body-weights rose by $3^{\circ}-40 \mathrm{~g}$ in 8 weeks. The brains of the undernourished animals, though lighter than those of well-nourished controls, contained the same concentration of cholesterol. In a preliminary experiment in which weanling rats were fed on a $5 \%$ casein diet with sucrose as the carbohydrate, the body-weights remained constant for 4 weeks (Dickerson, 1968). There was no increase in brain weight, but again the concentration of cholesterol in the brain was normal for the chronological age. This experiment has now been repeated, and the study extended to include the effects of subsequent rehabilitation on the skeleton, the brain, skeletal muscle and the liver.

\section{MATERIALS AND METHODS}

A total of seventy-five weanling male rats of an inbred black and white hooded strain which had been suckled in litters of eight pups since birth were divided randomly amongst the various treatments. Fifteen were killed at $24 \mathrm{~d}$ of age as 'initial controls'. Of the remainder, thirty were fed on a 'protein-deficient' diet containing $5 \%$ casein with $0.2 \%$ methionine, $15 \%$ maize oil, $70 \%$ sucrose and adequate minerals and vitamins, and thirty were given a 'control diet' containing $25 \%$ casein, and $50 \%$ sucrose but similar amounts of methionine, maize oil, minerals and vitamins. The animals had free access to water. The experimental diets were offered for 4 weeks from $24 \mathrm{~d}$ of age. At $52 \mathrm{~d}$ of age fifteen animals on the protein-deficient diet and fifteen on the control diet were killed. The remaining fifteen animals that had been fed on the protein-deficient diet were transferred to the control diet and fed along with the remaining fifteen control animals until they were all killed at $\mathrm{I} 4 \mathrm{O} \mathrm{d}$ of age. All animals were killed with diethyl ether, the brain was removed as described by Dobbing (1964), dissected into cerebellum, forebrain and brain stem (Dickerson \& Jarvis, 1970), and the parts were weighed. The liver was removed, blotted to remove as much blood as possible and weighed. The quadriceps muscles were also removed and weighed. The tissues were kept at $-15^{\circ}$ until analysed. The skeletons were X-rayed and the skeletal dimensions measured; maturity was assessed as previously described (Hughes \& Tanner, $1970 a, b)$. The protein-deficient and control animals were weighed at weekly intervals throughout the experiment.

The lipids were extracted from the brain samples (Folch, Lees \& Stanley, 1957) and cholesterol was determined in the extract (Lefflcr, 1959). DNA was separated from samples of homogenized brain, skeletal muscle and liver as described by Zamenhof, Bursztyn, Rich \& Zamenhof $\left(1_{96}{ }_{5}\right)$ and the DNA determined by the diphenylamine reaction (Burton, 1956). The values were then expressed as DNA-phosphorus (DNA-P). 


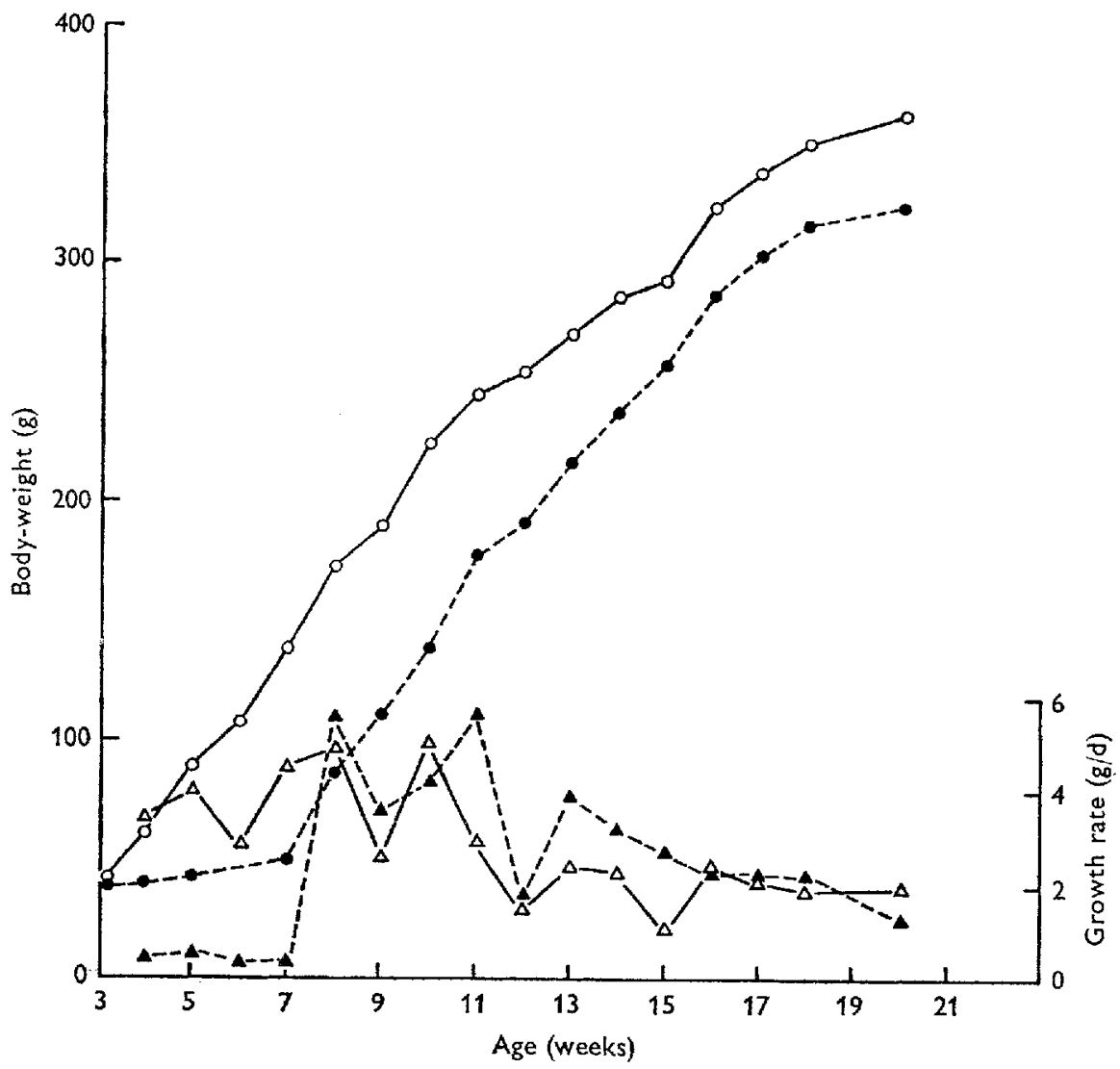

Fig. I. Effect of giving a $5 \%$ casein diet to weanling rats for $28 \mathrm{~d}$ and of subsequent rehabilitation on body-weight and growth rate. For control animals, body-weight shown $\mathrm{O}-\mathrm{O}$, and growth rate $\triangle-\triangle$, for malnourished animals, body-weight shown - - - , and growth rate A- - A.

\section{RESULTS}

Fig. I shows the changes in body-weight of the rats with age. Each point is the mean body-weight of all the animals available. During the 4 weeks that they were on the low-protein diet, the body-weights of the rats rose by $7 \mathrm{~g}$, a mean rise of almost $2 \mathrm{~g}$ / week. During the same time, the body-weights of the controls rose by $1 \mathrm{i} 6 \mathrm{~g}$, a mean rise of $29 \mathrm{~g} /$ week. When they were transferred to the control diet, the growth rate of the previously malnourished animals rose from $0.25 \mathrm{~g} / \mathrm{d}$ to a mean value of $4.7 \mathrm{~g} / \mathrm{d}$ during the first $28 \mathrm{~d}$ of rehabilitation. This was significantly higher $(P<0.0 \mathrm{I})$ than the growth rate of the controls, $3.8 \mathrm{~g} / \mathrm{d}$ over the same period, but although the higher growth rate was sustained for a further $28 \mathrm{~d}$, the body-weights of the rehabilitated rats at $\mathrm{I} 4 \mathrm{O} \mathrm{d}$ of age were lower than those of the controls.

Table $\mathrm{I}$ shows that all the bones of the skeletons of the protein-deficient rats, with the exception of the width of the pelvis, were larger than those of the initial controls. Skeletal development, as measured by the bone maturity score (BMS), was also more advanced. The skeletons of the protein-deficient rats were considerably smaller than 


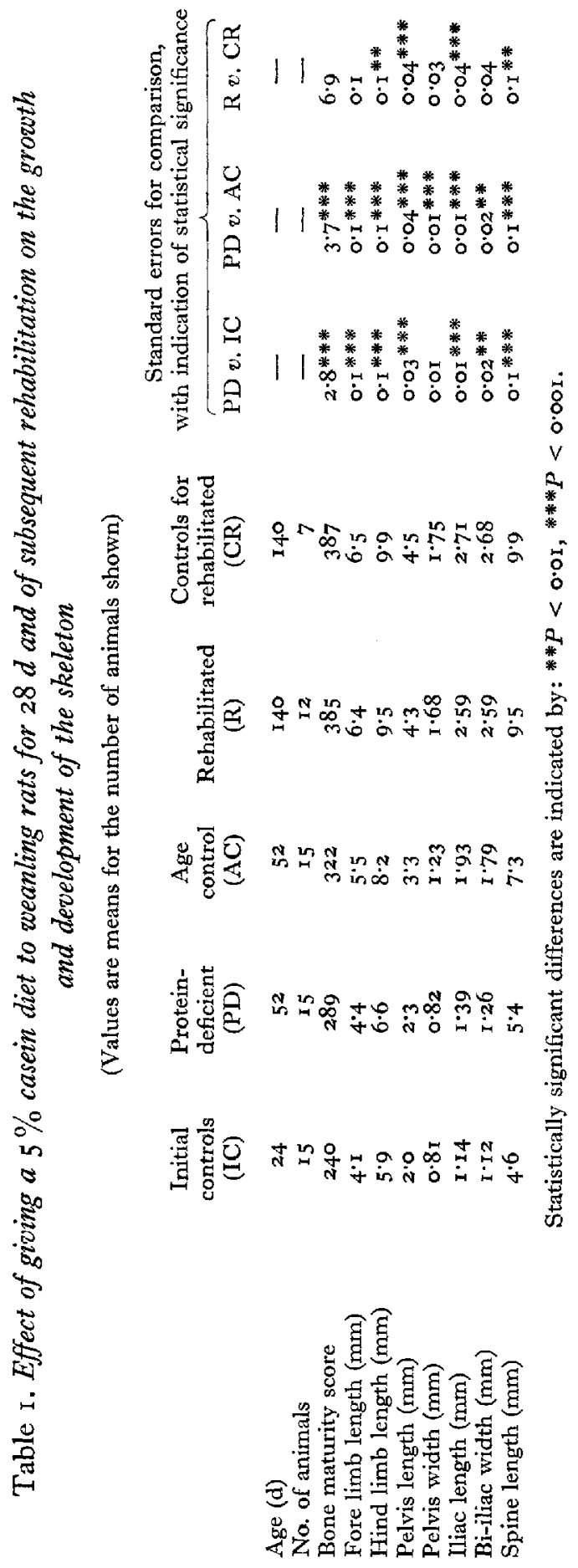


Vol. 27

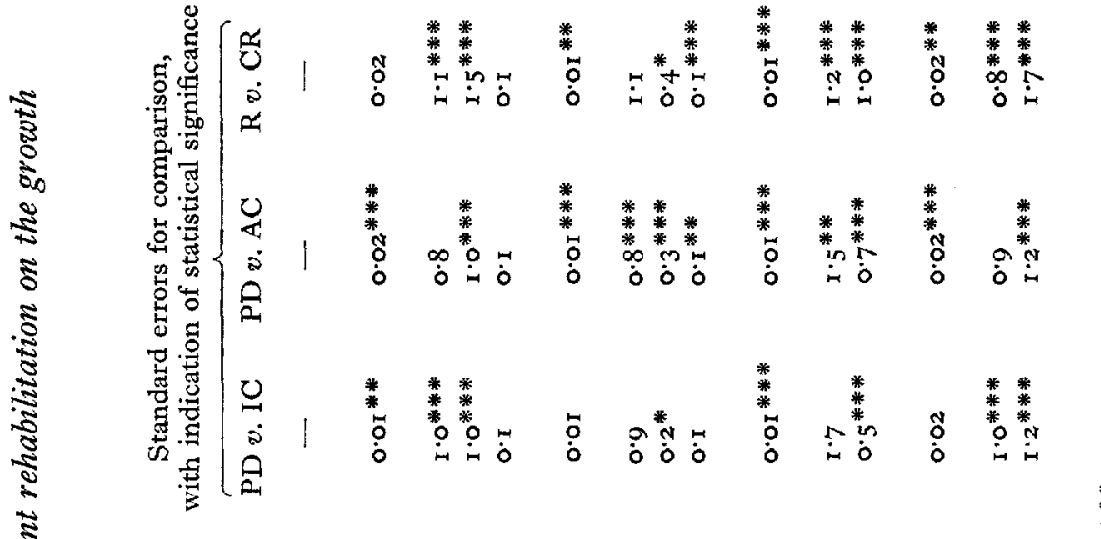

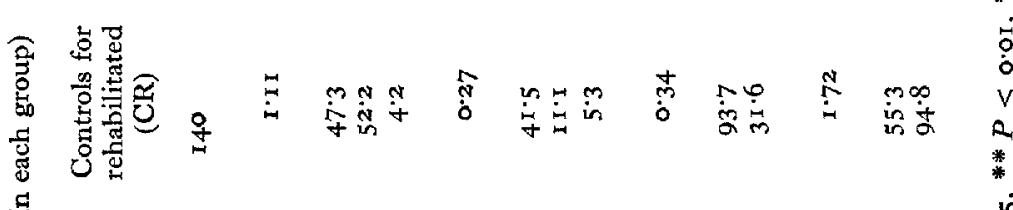

हี

(1)

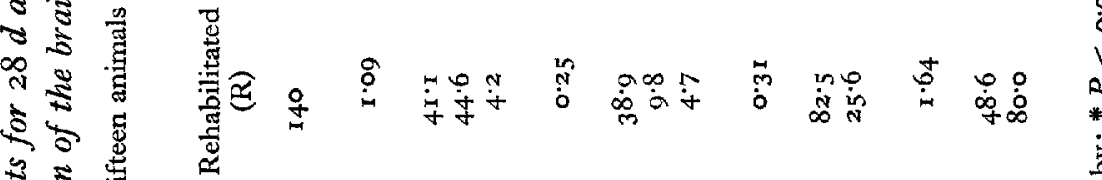

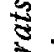

s.

है हี

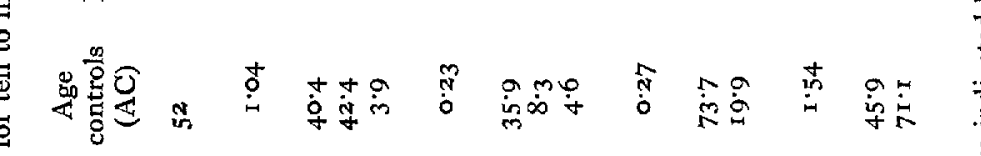

8 ह

:

胥

g

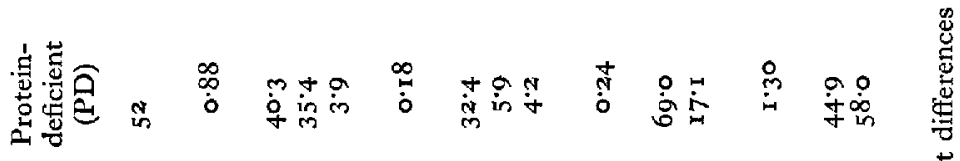

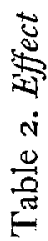

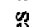

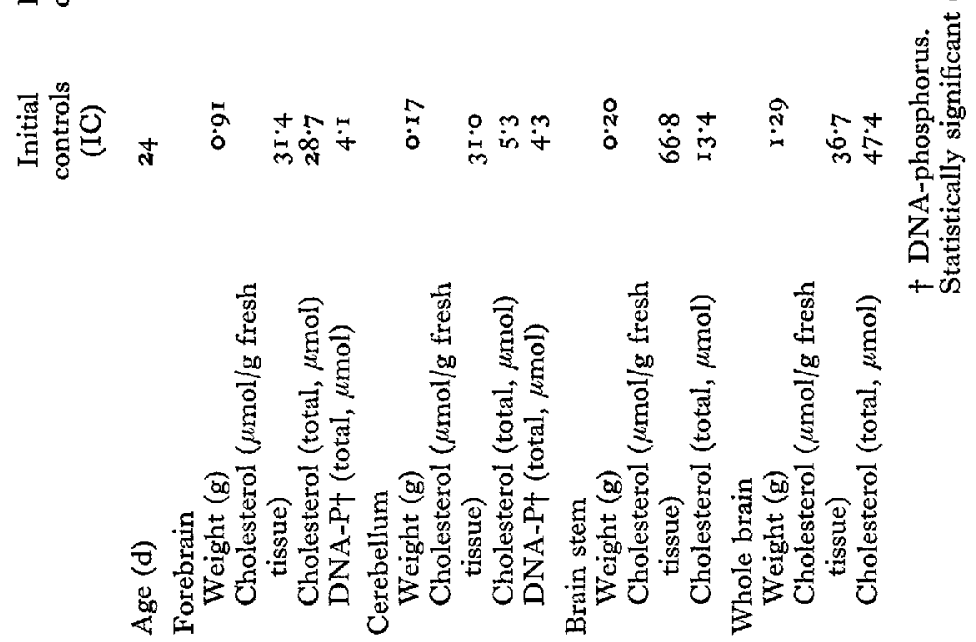




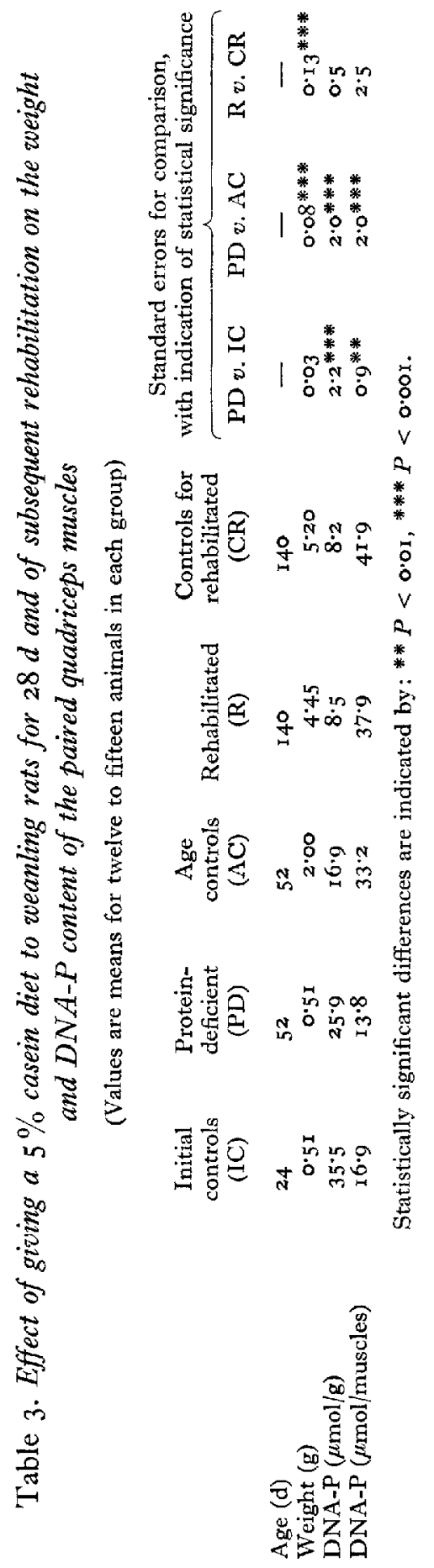


Table 4. Summary of previous studies with rats of the effects of post-weaning malnutrition on brain growth and development

(Differences in present study shown in parentheses)

Reference

Dobbing \&

Widdowson ( 1965 )

Dickerson \& Walmsley ( 1967 )

Graystone \& Cheek (1969)
Experimental technique and results

Ten pups in litter (eight pups); experiment done on males $20-3 \circ \mathrm{g}$ body-weight (males approx. $40 \mathrm{~g}$ body-weight); pellet diet (diet $4 \mathrm{I} \mathrm{B}$; Bruce, I957) in restricted amounts ( $5 \%$ casein diet $a d$ lib.); growth restricted to 5 g/week (2 g per week); growth restriction $56 \mathrm{~d}(28 \mathrm{~d})$; rehabilitation $56 \mathrm{~d}(5 \circ \mathrm{d})$; body-weight completely recovered on rehabilitation (incomplete recovery); brain weight completely recovered (incomplete recovery of whole brain, complete recovery of forebrain); complete recovery of cholesterol concentration in whole brain (incomplete recovery in whole brain, forebrain and brain stem)

As above, with no significant rise after weaning in whole brain DNA-P (no rise in forebrain DNA-P, rise in cerebellum DNA-P with incomplete recovery on rehabilitation)

Sprague-Dawley rats (black and white hooded); undernourished $26 \mathrm{~d}$ at $60 \%$ level of Purina Chow, $23 \%$ protein; cerebrum only analysed for DNA by fluorometric method of Kissane \& Robbins ( 1958 ) (forebrain DNA by diphenylamine reaction; Burton, 1956); rise in DNA in controls, reduction in undernourished (no rise in DNA in forebrain in controls, no change in malnourished)

those of the control animals of the same chronological age. In the rehabilitated animals the hind limb, pelvis, iliac and spine lengths and the bi-iliac width were smaller than the corresponding bones of the control animals. There was no difference in the length of the fore limb, the width of the pelvis or the BMS.

The forebrains of the protein-deficient animals weighed less than those of the initial controls, whereas the brain stem weighed more (Table 2). The weight of the cerebellums was practically the same. These differences in the weights of the three parts of the brain tended to cancel each other out, for the difference in the weight of the whole brain was not significant. The brains of the protein-deficient animals did, however, weigh less than those of controls of the same age and this was true also for each part. On rehabilitation, the forebrain grew to its normal weight for age, whereas the cerebellum, brain stem and whole brain did not.

The concentration of cholesterol in the forebrain rose during the $28 \mathrm{~d}$ of eating the protein-deficient diet and reached a value similar to that found in the normal animals of the same age. In the rehabilitated animals the concentration of cholesterol in the forebrain was almost the same as in the malnourished ones, and significantly below that in their controls. The amount of DNA-P in the forebrain remained practically unchanged during the dietary restriction and subsequent rehabilitation.

The concentrations of cholesterol in the cerebellum and brain stem of the proteindeficient rats were not significantly different from those in the controls killed at the start of the dietary restriction, but were lower than those in the controls of the same age. However, in the rehabilitated animals the concentration in the cerebellum was not significantly lower than in the corresponding controls, whereas in the brain stem, the concentration was significantly lower. The amount of DNA-P in the cerebellum did not change during the dietary restriction and was significantly lower than in the 
controls of the same age. The absolute amount of DNA-P in the cerebellum of the controls at $140 \mathrm{~d}$ was higher than in the controls of $52 \mathrm{~d}$. The amount in the cerebellums of the rehabilitated animals was significantly less than in their controls.

The result of these changes in the parts of the brain was that the concentration of cholesterol in the whole brain was similar in the deficient animals to that in controls of the same chronological age, whereas that in the rehabilitated animals was lower than in the corresponding controls.

The mean weights of the quadriceps muscles of the protein-deficient animals were the same as that of their initial controls (Table 3 ). After the period of rehabilitation the muscles weighed less than those of the controls. The concentration of DNA-P in the muscles of the protein-deficient animals was lower than in those of the initial controls but not as low as that in controls of the same age. The absolute amount of DNA-P in the 'protein-deficient' muscles was lower than in the initial controls, and only about $40 \%$ of the amount in controls of the same age. After rehabilitation the concentration of DNA-P was similar to that in control animals of the same age, and the absolute amount of DNA-P in the rehabilitated muscles was not significantly lower than in the controls.

The liver of the protein-deficient animals weighed more $\left(2 \cdot 7^{2} \mathrm{~g}\right)$ than that of the initial controls ( $1.97 \mathrm{~g}$ but less than that of controls) of the same age $(9 \cdot 3 \mathrm{~g}$ ). After rehabilitation, the liver weight was practically the same ( $14.8 \mathrm{~g}$ ) as that of controls of the same age ( $14.9 \mathrm{~g}$ ) and there was no significant difference in the content of DNA-P (24.1 $\mu \mathrm{mol}$ in livers of rehabilitated animals and $24.7 \mu \mathrm{mol}$ in controls).

\section{DISCUSSION}

In this experiment the growth of weanling rats was severely retarded for 4 weeks by allowing them free access to a $5 \%$ casein diet in which sucrose was the carbohydrate. When transferred to the control diet containing $25 \%$ casein, the previously retarded animals grew well and showed the expected growth spurt. This period of rapid growth was maintained for about 8 weeks, but was not great enough to bring the body-weights up to those of controls of the same age that had been given the $25 \%$ casein diet since weaning. The animals were 20 weeks old when they were killed, and it seemed unlikely that, even if the experiment had been prolonged, they would have attained a normal weight since their growth curve had been parallel to that of the controls for $3-4$ weeks before the experiment was terminated. This result is different from that obtained in previous experiments on undernourished weanling rats (Dobbing \& Widdowson, 1965; Dickerson \& Walmsley, I967; see Table 4), but a possible explanation for the apparent recovery in those experiments may have been the rather poor growth of the controls (Dobbing, I968).

The skeleton continued to grow slowly, and to develop during the period of dietary restriction. The dietary restriction did, however, have a small, but permanent stunting effect on some of the bones. Thus, as in another study of the effects of severe undernutrition before weaning (Dickerson and Hughes, in preparation), the spine was significantly shorter and so too were the pelvis and the ilium. It was suggested that in the previous experiment the permanent stunting resulted from the fact that the period of 
growth restriction started before the bones had reached their peak rate of growth. This was in contrast to the limb bones, whose peak rate of growth was reached before the undernutrition became very severe. In the present experiment the dietary restriction occurred over the age range when the peak growth rate of the pelvis is normally reached (i.e. $35^{-42}$ d), and hence a similar explanation of the failure of the pelvic bones to recover completely seems possible. In the experiment described here, there was a difference in the recovery of the fore and hind limbs. The failure of the latter to reach a normal length could be due to the fact that the period of dietary restriction deprived the bones of a second, prepubertal, growth spurt (Hughes \& Tanner, 1970a). A similar growth spurt does not occur in the fore limb.

The diffcrent parts of the brain grow and develop at different rates (Dickerson, Dobbing \& McCance, 1967 ) and this explains certain aspects of the effect of undernutrition upon them. In the present study, growth of the forebrain was stopped by giving the low-protein diet. Complete recovery in weight on rehabilitation probably occurred because the absolute amount of DNA-P, and hence the number of cells, had already attained the adult value. There was no evidence of the post-weaning increase in DNA-P content that Graystone \& Cheek (1969) have described in the cerebral hemispheres (see Table 4). The growth of the cerebellum was also completely prevented by the protein-deficient diet. Complete recovery on rehabilitation did not, however, occur, and this was probably due to a partial failure of cell multiplication as shown by a lower DNA-P content. In the cerebellum there was a significant increase in DNA-P content after $52 \mathrm{~d}$ of age. This increase does not appear to have been reported before, but it has been confirmed in further work with ten animals.

The increase in weight of the brain stem during the period of restricted growth was probably due to the growth in thickness of the medulla, since growth in thickness of the spinal cord has been found to be closely related to chronological age (Dickerson et al. 1967; Dickerson \& Walmsley, I967).

The rise in cholesterol concentration in the brain occurs with increase in chronological age rather than body-weight (Dickerson, 1968). The result of the present study suggests that a protein-deficient diet, in contrast to a predominantly calorie-deficient one (Dobbing \& Widdowson, r965; Dickerson \& Walmsley, 1967; see Table 4), permanently reduces the ability of the forebrain and brain stem to synthesize cholesterol. The degree of growth retardation in the present experiment was, however, greater than in the experiments with calorie-deficient diets.

Winick \& Noble (1966) reported that undernutrition from 2i to $4^{2} \mathrm{~d}$ of age had a permanent stunting effect on the subsequent growth of skeletal muscle and the liver. They attributed this to the fact that undernutrition, although after weaning, had nevertheless taken place before these organs had accumulated their mature number of cells. In this experiment, a rather more severe retardation of body-weight resulted in a cessation of muscle growth. On rehabilitation, the quadriceps muscles failed to attain the normal weight, but there was only inconclusive evidence that they contained a smaller amount of DNA. Winick \& Noble used the gastrocnemius muscle in their work, whereas the quadriceps was used in the present study. There seems to be little information about the effect of undernutrition on different muscles in mammals, 
though differences have been reported in cockerels (Dickerson \& McCance, 1960).

Maintaining rats on a diet containing $5 \%$ casein did not prevent the liver attaining a normal weight on rehabilitation. These animals were, however, rehabilitated on a diet that contained a higher concentration of protein $(25 \%)$ than is normally found in stock diets ( $\mathrm{I} 8-2 \mathrm{I} \%$ ), and it may be that this accounts for the difference between the results reported here and those of Winick \& Noble (1966).

There is now substantial evidence, both in experimental animals and in man, that a period of growth retardation in early life is likely to have some permanent effects on later growth and development. The present study suggests that a retardation of growth rather later in life may also have some permanent effects. This period of life seems to warrant more detailed study, particularly in view of the fact that undernutrition may occur in preschool children in many parts of the world.

The authors thank Professor J. M. Tanner for his continuing interest in this work, and the Nuffield Foundation for its financial support to the Department of Growth and Development at the Institute of Child Health.

\section{REFERENCES}

Bruce, H. M. (1957). Stud. Fertil. 9, 90.

Burton, K. (1956). Biochem. $7.62,3 \times 5$.

Dickerson, J. W. T. (1968). In Calorie Deficiencies and Protein Deficiencies p. 329 [R. A. McCance and E. M. Widdowson, editors]. London: Churchill.

Dickerson, J. W. T., Dobbing, J. \& McCance, R. A. (r967). Proc, R. Soc. B x66, 396.

Dickerson, J. W. 'T. \& Jarvis, J. (1970). Proc. Nutr. Soc. 29, 4 A.

Dickerson, J. W. T. \& McCance, R. A. (1960). Br. F. Nutr. 14, 33r.

Dickerson, J. W. T. \& Walmsley, A. W. (1967). Brain 90, 897 .

Dobbing, J. (1964). Proc. R. Soc. B 159, 503.

Dobbing, J. ( ( 968). In Applied Neurochemistry p. 287 [A. N. Davison and J. Dobbing, editors]. Oxford: Blackwell Scientific Publications.

Dobbing, J. \& Widdowson, E. M. (1965). Brain 88, 357.

Folch, J., Lees, M. \& Stanley, G. H. S. (1957). F. biol. Chem. 226, 497.

Graystone, J. E. \& Cheek, D. B. (I 969). Pediat. Res. 3, 66.

Hughes, P. C. R. \& 'Tanner, J. M. (r970a). F. Anat. 1o6, 349.

Hughes, P. C. R. \& Tanner, J. M. (1970b). F. Anat. 106, 37 I.

Kennedy, G. C. (1957-8). F. Endocr. 16, 9.

Kissane, J. M. \& Robbins, E. (1958). F. biol. Chem. 233, т84.

Leffler, H. H. (1959). Am. \%. clin. Path. 31, 3 ro.

Widdowson, E. M. \& McCance, R. A. (1960). Proc. R. Soc. B 152, 188.

Winick, M. \& Noble, A. (1966). F. Nutr. 89, 300.

Zamenhof, S., Bursztyn, H., Rich, K. \& Zamenhof, P. J. (1965). F. Neurochem. Ir, 505. 